Eupatilin protects gastric epithelial cells from oxidative damage and down-regulates genes responsible for the cellular oxidative stress. Pharm Res 2008;25:1355-1364.

5. Lee SH, Bae EA, Park EK, Shin YW, Baek NI, Han EJ, et al. Inhibitory effect of Eupatilin and jaceosidin isolated from Artemisia princeps in IgE-induced hypersensitivity. Int Immunopharmacol 2007;7:1678-1684.

6. Engelking LJ, Kuriyama $\mathrm{H}$, Hammer RE, Horton JD, Brown MS, Goldstein JL, et al. Overexpression of Insig-1 in the livers of transgenic mice inhibits SREBP processing and reduces insulin-stimulated lipogenesis. J Clin Invest 2004; 113:1168-1175.

7. Smith TM, Gilliland K, Clawson GA, Thiboutot D. IGF-1 induces SREBP-1 expression and lipogenesis in SEB-1 sebo- cytes via activation of the phosphoinositide 3-kinase/Akt pathway. J Invest Dermatol 2008;128:1286-1293.

8. Trivedi NR, Cong Z, Nelson AM, Albert AJ, Rosamilia LL, Sivarajah $S$, et al. Peroxisome proliferator-activated receptors increase human sebum production. J Invest Dermatol 2006; 126:2002-2009.

9. Ferré P. The biology of peroxisome proliferator-activated receptors: relationship with lipid metabolism and insulin sensitivity. Diabetes 2004;53 Suppl 1:S43-S50.

10. Choi $Y$, Jung $Y$, Kim SN. Identification of Eupatilin from Artemisia argyi as a selective PPARa agonist using affinity selection ultrafiltration LC-MS. Molecules 2015;20:1375313763.

\title{
Can Body Mass Index and/or Waist Circumference Be the Risk Factors of Chronic Spontaneous Urticaria?: A Nationwide Population-Based Study
}

\author{
Yoon Seob Kim, Kyungdo Han ${ }^{1}$, Ji Hyun Lee, Jun Young Lee, Young Min Park \\ Department of Dermatology, Seoul St. Mary's Hospital, The Catholic University of Korea, ${ }^{1}$ Department of Medical Statistics, College of \\ Medicine, The Catholic University of Korea, Seoul, Korea
}

Dear Editor:

Several studies have suggested an association between chronic spontaneous urticaria (CSU) and body mass index $(\mathrm{BMI})^{1-3}$ or metabolic syndrome ${ }^{1,4}$. In contrast, a French study reported that obesity was not associated with severe $\mathrm{CSU}^{5}$. There is little evidence that waist circumference (WC), another scale which correlates well with visceral obesity, is associated with CSU. We hypothesized that obesity could be associated with increased CSU risk. The aim of our study was to investigate the impact of BMI and/or WC on the risk for CSU in an adult Korean population using a nationwide database. The study was approved by the Institutional Review Board of The Catholic University of Korea (IRB no. KC16EISE0852).

The health check-up database, a sub-dataset of the Korean National Health Insurance Service (NHIS) database (2002 2015), was used for data collection. NHIS subscribers are advised to have biannual health check-ups including height,

Received September 13, 2018, Revised November 15, 2018, Accepted for publication January 2, 2019

Corresponding author: Young Min Park, Department of Dermatology, Seoul St. Mary's Hospital, College of Medicine, The Catholic University of Korea, 222 Banpo-daero, Seocho-gu, Seoul 06591, Korea. Tel: 82-2-2258-6223, Fax: 82-2-599-9950, E-mail: yymmpark6301@hotmail.com ORCID: https://orcid.org/0000-0002-3631-0807

This is an Open Access article distributed under the terms of the Creative Commons Attribution Non-Commercial License (http://creativecommons.org/ licenses/by-nc/4.0) which permits unrestricted non-commercial use, distribution, and reproduction in any medium, provided the original work is properly cited.

Copyright $\odot$ The Korean Dermatological Association and The Korean Society for Investigative Dermatology 
weight, WC, systolic and diastolic blood pressure, and laboratory examinations, which constitute the health checkup database. Data from all Korean subjects aged $\geq 20$ years from January 1, 2002, to December 31, 2015, were extracted for analysis. Among them, subjects who had undergone at least one biannual health examination between 2009 and 2012 were followed up from the date of their health check-up until 2015 as the endpoint of the occurrence of CSU. For subjects with more than twice health check-ups, the first result was used. The incidence was calculated as the number of patients with newly diagnosed CSU divided by the total person-years at risk. Because a diagnostic code for CSU does not exist in the International Classification of Diseases (ICD)-10, a diagnosis of CSU was defined when one of the following two criteria were met: either 1) two outpatient diagnoses of L50.1 (idiopathic urticaria), L50.8 (other specified urticaria), or L50.9 (urticaria, unspecified) at least 6 weeks apart in one year; or 2) one outpatient diagnosis of L50.1, L50.8, or L50.9 plus one diagnosis of T78.3 (angioneurotic edema) at least 6 weeks apart in one year. This definition was validated in American study using ICD-9 based diagnostic code to have a positive predictive value of $90.4 \%$ and a sensitivity of $71.1 \%$. To ensure that only newly di- agnosed subjects were included, at-risk subjects were defined as those who had not been diagnosed with CSU between 2002 and the date of the health check-up. The high BMI (general obesity) group was defined as subjects with BMI more than $\geq 25 \mathrm{~kg} / \mathrm{m}^{2}$, and the high WC (abdominal obesity) group was defined as subjects with WC more than $90 \mathrm{~cm}$ in men or $85 \mathrm{~cm}$ in women, according to the Korean definition for obesity ${ }^{7}$. Comorbidities were identified using the results of laboratory examinations or diagnostic codes and any associated medications prescribed during the study period. Cox proportional hazards regression analyses were conducted to calculate the multivariable hazard ratio (HR) and 95\% confidence interval (Cl) for the association of $\mathrm{BMI}$ and WC with the incidence of CSU after adjusting for demographic factors of age, gender, smoking status, alcohol consumption, and exercise, and comorbidities of diabetes mellitus, hypertension, and hyperlipidemia. Detailed histories of smoking status, alcohol consumption, and physical activity were obtained by questionnaire, and they were further classified into two categories each for smoking (no/past, and current), alcohol ( $\geq 30 \mathrm{~g}$ daily or no). Socioeconomic status was categorized into two groups based on income level $(<20 \%$ or $\geq 20 \%$ ).

Table 1. A comparison of the clinical characteristics of the study population according to the presence or absence of chronic spontaneous urticaria

\begin{tabular}{lrrr}
\hline & No CSU $(\%)(\mathrm{n}=22,741,513)$ & CSU $(\%)(\mathrm{n}=289,493)$ & $p$-value \\
\hline Mean age (yr) & $47.6 \pm 14.4$ & $53.3 \pm 14.4$ & $<0.0001$ \\
$20 \sim 39$ & $6,661,651(29.3)$ & $49,550(17.1)$ & $<0.0001$ \\
$40 \sim 64$ & $12,954,599(57.0)$ & $168,891(58.3)$ & \\
$\geq 65$ & $3,125,263(13.7)$ & $71,052(24.5)$ & $<0.0001$ \\
Gender (women) & $11,176,012(49.1)$ & $159,480(55.1)$ & $<0.0001$ \\
Mean BMI & $23.7 \pm 3.3$ & $23.9 \pm 3.2$ & $<0.0001$ \\
High WC & $6,402,141(28.2)$ & $101,341(35.0)$ & $<0.0001$ \\
Current smoker & $5,608,991(24.7)$ & $57,864(20.0)$ & $<0.0001$ \\
Heavy drinker & $1,511,135(6.6)$ & $15,233(5.3)$ & $<0.0001$ \\
Income ( $\geq 20 \%)$ & $16,671,929(73.3)$ & $209,663(72.4)$ & $<0.0001$ \\
DM & $2,096,912(9.2)$ & $36,127(12.5)$ & $<0.0001$ \\
HTN & $5,954,519(26.2)$ & $98,731(34.1)$ & $<0.0001$ \\
Hyperlipidemia & $4,351,294(19.1)$ & $72,802(25.1)$ & $<0.0001$ \\
Mean SBP & $122.2 \pm 15.2$ & $123.3 \pm 15.4$ & $<0.0001$ \\
Mean DBP & $76.1 \pm 10.1$ & $76.4 \pm 10.0$ & $<0.0001$ \\
Mean glucose & $97.5 \pm 23.4$ & $98.9 \pm 24.4$ & $<0.0001$ \\
Mean total cholesterol & $194.6 \pm 36.9$ & $196.9 \pm 37.9$ & $<0.0001$ \\
Mean HDL & $55.5 \pm 16.7$ & $55.0 \pm 18.1$ & $<0.0001$ \\
Mean LDL & $113.4 \pm 33.6$ & $115.2 \pm 34.6$ & \\
\hline
\end{tabular}

Data are expressed as mean \pm standard deviation for continuous variables and numbers (percentages) for binary variables. CSU: chronic spontaneous urticarial, BMI: body mass index, WC: waist circumference, DM: diabetes mellitus, HTN: hypertension, SBP: systolic blood pressure, DBP: diastolic blood pressure, HDL: high-density lipoprotein, LDL: low-density lipoprotein. $p$-values represent the comparison of clinical characteristics between subjects who did and did not develop CSU using Student's t-tests for continuous variables and the chi-square test for categorical variables. 
Table 2. Multivariate Cox proportional-hazards regression analysis of the association between either the BMI or the waist circumference and the CSU incidence rate

\begin{tabular}{|c|c|c|c|c|c|}
\hline Group & Number & CSU & Incidence rate* & Model 1 & Model 2 \\
\hline \multicolumn{6}{|l|}{ BMI $\left(\mathrm{kg} / \mathrm{m}^{2}\right)$} \\
\hline$<18.5$ & 935,423 & 10,004 & 2.019 & 1 (reference) & 1 (reference) \\
\hline $18.5 \leq \mathrm{BMI}<23$ & $9,162,223$ & 107,997 & 2.192 & $1.02(1.00 \sim 1.04)$ & $1.02(1.00 \sim 1.04)$ \\
\hline $23 \leq \mathrm{BMI}<25$ & $5,567,473$ & 72,891 & 2.410 & $1.06(1.04 \sim 1.08)$ & $1.05(1.03 \sim 1.07)$ \\
\hline $25 \leq \mathrm{BMI}<30$ & $6,512,383$ & 87,546 & 2.484 & $1.09(1.06 \sim 1.11)$ & $1.06(1.04 \sim 1.09)$ \\
\hline$\geq 30$ & 853,504 & 11,055 & 2.452 & $1.12(1.09 \sim 1.15)$ & $1.08(1.05 \sim 1.11)$ \\
\hline \multicolumn{6}{|l|}{ WC (cm) } \\
\hline$<80$ & $8,600,674$ & 91,438 & 1.986 & 1 (reference) & 1 (reference) \\
\hline $80 \leq W C<85$ & $5,308,064$ & 65,337 & 2.268 & $1.04(1.03 \sim 1.05)$ & $1.03(1.02 \sim 1.04)$ \\
\hline $85 \leq W C<90$ & $4,488,788$ & 61,711 & 2.531 & $1.09(1.07 \sim 1.10)$ & $1.07(1.06 \sim 1.08)$ \\
\hline $90 \leq \mathrm{WC}<95$ & $2,682,123$ & 39,811 & 2.740 & $1.13(1.12 \sim 1.15)$ & $1.11(1.10 \sim 1.13)$ \\
\hline $95 \leq \mathrm{WC}<100$ & $1,238,068$ & 19,717 & 2.958 & $1.18(1.16 \sim 1.20)$ & $1.15(1.13 \sim 1.17)$ \\
\hline $100 \leq \mathrm{WC}<105$ & 476,348 & 7,726 & 3.039 & $1.20(1.17 \sim 1.23)$ & $1.17(1.14 \sim 1.19)$ \\
\hline $105 \leq \mathrm{WC}<110$ & 161,007 & 2,541 & 2.991 & $1.18(1.14 \sim 1.23)$ & $1.14(1.10 \sim 1.19)$ \\
\hline$\geq 110$ & 75,934 & 1,212 & 3.084 & $1.28(1.21 \sim 1.35)$ & $1.23(1.16 \sim 1.30)$ \\
\hline
\end{tabular}

Values are presented as hazard ratio (95\% confidence interval). Model 1 was adjusted for age and gender. Model 2 was adjusted for age, gender, smoking status, alcohol status, exercise status, household income, and the presence of diabetes mellitus, hypertension and hyperlipidemia. BMI: body mass index, CSU: chronic spontaneous urticarial, WC: waist circumference. *Per 1,000 person-years.

In total, 23,031,006 subjects were followed for a mean duration of $5.4 \pm 1.1$ years, and 289,493 cases of CSU were identified during the follow-up period. The clinical characteristics of the study population classified according to the development of CSU were summarized (Table 1). Those who developed CSU were more likely to be elderly and women and also to have a higher BMI, WC, and more comorbidities than subjects who did not $(p<0.0001)$. Table 2 displays the results of the adjusted HR of CSU stratified by $\mathrm{BMI}$ and WC after accounting for demographic factors and comorbidities. The adjusted HR for CSU was the lowest in subjects with a BMI $<18.5 \mathrm{~kg} / \mathrm{m}^{2}$ (HR, 1; reference) and a $W C<80 \mathrm{~cm}$ (HR, 1; reference), whereas the highest rates were seen for those with a BMI $>30 \mathrm{~kg} / \mathrm{m}^{2}(\mathrm{HR}, 1.08$; $95 \% \mathrm{Cl}, 1.05 \sim 1.11)$ and a $\mathrm{WC}>110(\mathrm{HR}, 1.23 ; 95 \% \mathrm{Cl}$, $1.16 \sim 1.30$ ), respectively. Overall, higher BMIs and WCs were weakly associated with an increasing tendency for an adjusted HR of CSU.

Population-based study from Italy found a significantly increased risk of CSU in subjects with obesity defined by $\mathrm{BMI}$ in the study population including subjects from a primary care clinic only ${ }^{2}$. Our study provided possible evidence that obesity could have a role in the development of CSU. Furthermore, we found that abdominal obesity had a greater impact on the risk of CSU than general obesity These results are in line with a large body of evidence indicating that abdominal obesity has greater impact on obesity-related health risks than general obesity ${ }^{8}$. Although the precise mechanism linking obesity and CSU remains unknown, systemic inflammatory cytokines are associated with both obesity and CSU presence or disease activity ${ }^{9,10}$. The systemic inflammatory response resulting from obesity is thought to be involved in the pathogenesis of $\mathrm{CSU}^{3,4,9,10}$. Further studies are needed to elucidate any causal relationship for the obesity-CSU link.

The major strength of our study was a long-term retrospective cohort study design using nationwide database. Moreover, both BMI and WC were measured using a consistent method in real-world clinical practice, validating the results. Limitation was the possibility of false diagnoses. The effects of unidentified confounding factors could not be adjusted. To overcome the limitations, we used a validated definition of CSU and adjusted for possible confounding factors, although the validation study has not been done in Korea. We excluded the patients who did not undergo the health examination, which makes it difficult to generalize the results. In conclusion, our nationwide, population-based study demonstrated that both higher BMI and higher WC were weakly associated with an increased risk of CSU after adjusting for demographic factors and comorbidities. The proposed obesity-CSU link could expand our understanding of the pathogenesis and comorbidities of CSU.

\section{ACKNOWLEDGMENT}

This study used customized research data (NHIS-2017-1036) released by the NHIS. The authors declare no con- 
flict of interest with the NHIS. The authors alone are responsible for the content and writing of this paper and would like to thank Jin Heon Jung for assisting with data analysis.

\section{CONFLICTS OF INTEREST}

The authors have nothing to disclose.

\section{ORCID}

Yoon Seob Kim, https://orcid.org/0000-0003-1660-010X Kyungdo Han, https://orcid.org/0000-0002-6096-1263 Ji Hyun Lee, https://orcid.org/0000-0002-3671-502X Jun Young Lee, https://orcid.org/0000-0002-8650-1759 Young Min Park, https://orcid.org/0000-0002-3631-0807

\section{REFERENCES}

1. Shalom G, Magen E, Babaev M, Tiosano S, Vardy DA, Linder $\mathrm{D}$, et al. Chronic urticaria and the metabolic syndrome: a cross-sectional community-based study of 11261 patients. J Eur Acad Dermatol Venereol 2018;32:276-281.

2. Lapi F, Cassano N, Pegoraro V, Cataldo N, Heiman F, Cricelli $\mathrm{I}$, et al. Epidemiology of chronic spontaneous urticaria: results from a nationwide, population-based study in Italy. Br J Dermatol 2016;174:996-1004.

3. Zbiciak-Nylec M, Wcisło-Dziadecka D, Kasprzyk M, Kulig A, Laszczak J, Noworyta M, et al. Overweight and obesity may play a role in the pathogenesis of chronic spontaneous urticaria. Clin Exp Dermatol 2018;43:525-528.
4. Ye YM, Jin HJ, Hwang EK, Nam YH, Kim JH, Shin YS, et al. Co-existence of chronic urticaria and metabolic syndrome: clinical implications. Acta Derm Venereol 2013;93:156160.

5. Soria A, Du-Thanh A, Amsler E, Raison-Peyron N, MathelierFusade $\mathrm{P}$, Staumont-Sallé $\mathrm{D}$, et al; French Urticaria Group (GUS) of French Dermatological Society. Obesity is not associated with severe chronic urticaria in a French cohort. J Eur Acad Dermatol Venereol 2018;32:e247-e249.

6. Cherepanov D, Raimundo K, Chang E, Eagan M, Zazzali JL, Solari PG, et al. Validation of an ICD-9-based claims algorithm for identifying patients with chronic idiopathic/ spontaneous urticaria. Ann Allergy Asthma Immunol 2015; 114:393-398.

7. Kim MK, Lee WY, Kang JH, Kang JH, Kim BT, Kim SM, et al. 2014 Clinical Practice Guidelines for overweight and obesity in Korea. Endocrinol Metab (Seoul) 2014;29:405409.

8. Janssen I, Katzmarzyk PT, Ross R. Waist circumference and not body mass index explains obesity-related health risk. Am J Clin Nutr 2004;79:379-384.

9. Grzanka A, Machura E, Misiolek M, Polaniak R, Kasperski J, Kasperska-Zajac A. Systemic inflammatory response and calcification markers in patients with long lasting moderatesevere chronic spontaneous urticaria. Eur J Dermatol 2015; 25:26-28.

10. Kasperska-Zajac A, Sztylc J, Machura E, Jop G. Plasma IL-6 concentration correlates with clinical disease activity and serum C-reactive protein concentration in chronic urticaria patients. Clin Exp Allergy 2011;41:1386-1391. 